\title{
Combined Deacetylation and PFI Refining Pretreatment of Corn Cob for the Improvement of a Two-Stage Enzymatic Hydrolysis
}

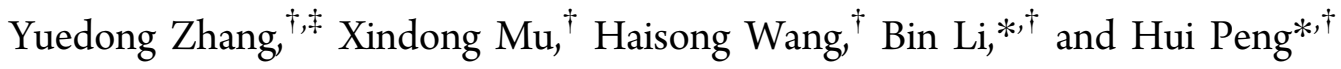

${ }^{\dagger}$ CAS Key Laboratory of Bio-based Materials, Qingdao Institute of Bioenergy and Bioprocess Technology, Chinese Academy of Sciences (CAS), Qingdao, Shandong 266101, People's Republic of China

${ }^{\ddagger}$ University of Chinese Academy of Sciences, Beijing 100049, People’s Republic of China

Supporting Information

ABSTRACT: A combined deacetylation and PFI refining pretreatment was applied to corn cob for the improvement of a twostage enzymatic hydrolysis. In stage 1 , the pretreated corn cob was first hydrolyzed by xylanase to produce xylo-oligosaccharides (XOS). In stage 2 , the solid residue isolated from stage 1 was further hydrolyzed by cellulase and $\beta$-glucosidase. $\mathrm{NaOH} \mathrm{Na}_{2} \mathrm{CO}$, and $\mathrm{Ca}(\mathrm{OH})_{2}$ were tested to remove acetyl groups in the process of deacetylation, and it was found that $\mathrm{Ca}(\mathrm{OH})_{2} \mathrm{could}$ be the most suitable alkali for deacetylation in this work. After deacetylation using $0.8 \mathrm{mmol}$ of $\mathrm{Ca}(\mathrm{OH})_{2} / \mathrm{g}$ of substrate and PFI refining, 50.5\% xylan in the raw material could be hydrolyzed into XOS. The corresponding xylan yield of stage 1 , the glucan yield of stage 2 , and the total sugar yield (all sugars released in the hydrolyzate) after the two-stage enzymatic hydrolysis were $0.306,0.305$, and $0.661 \mathrm{~g} / \mathrm{g}$ of corn cob, respectively.

KEYWORDS: corn cob, deacetylation, PFI refining, enzymatic hydrolysis, pretreatment, xylo-oligosaccharides (XOS)

\section{INTRODUCTION}

Xylo-oligosaccharides (XOS) are widely used as food and feed additives, which are considered soluble dietary fibers that have prebiotic activity, favoring the improvement of bowel and immune functions and having antimicrobial and other health benefits. ${ }^{1}$ Currently, XOS are usually produced from the separated xylan or pretreated xylan-rich biomass through acidic or enzymatic hydrolysis. ${ }^{2-7}$ Corn cob is an inexpensive and widely available resource of hemicellulose, which is usually chosen to produce XOS. ${ }^{2-4,6}$ In comparison to the chemical technologies (e.g., acid hydrolysis), the enzymatic hydrolysis is a better route for the food industries, because no toxic and undesired byproducts, such as furfural, are generated during the enzymatic process. ${ }^{1}$ However, the enzymatic substrates are mostly prepared by severe processes, which would not be friendly to the environment. Furthermore, the cellulose in the xylan-deprived corn cob residue should be used in a more economical and environmentally benign method.

For enzymatic hydrolysis of biomass, pretreatment is an important technology to alter the structure of cellulosic biomass to make cellulose/hemicellulose more accessible to enzymes. ${ }^{8}$ Nowadays, most commercially promising pretreatment processes [e.g., dilute acid/alkali pretreatment, ${ }^{9,10}$ steam explosion, ${ }^{11}$ sulfite pretreatment to overcome recalcitrance of lignocellulose (SPORL) method, ${ }^{12}$ etc.] are mainly aimed to remove the lignin or hemicellulose through severe chemical reactions or mechanical treatment with respect to the properties of feedstock and the goal of end use. For corn cob, which has a high hemicellulose (32-39\%) and low lignin content $(9-14 \%),{ }^{3,4,6}$ the acetyl groups on hemicellulose would be the main recalcitrance barrier, because the steric hindrance of acetyl groups could lower the activity of xylanase. ${ }^{13}$ Thus, the selective removal of acetyl groups from the backbone of xylan in feedstock by deacetylation can significantly improve the xylan digestibility and cellulose enzymatic hydrolysis. ${ }^{14}$ Acetyl xylan esterase, ${ }^{15,16}$ hydroxylamine solutions, ${ }^{17}$ and dilute alkali $^{13}$ can be used for deacetylation, and the conditions of deacetylation are usually milder compared to the traditional pretreatments, because acetyl groups are more reactive than the other enzymatic hydrolysis hinders (e.g., lignin). ${ }^{18}$ Furthermore, deacetylation could reduce the acetic acid generated during pretreatment and enzymatic hydrolysis, which could restrain the growth of microbes in the ethanol fermentation. ${ }^{19,20}$

On the other hand, many mechanical refining technologies that have been widely applied in the pulp industry were used to increase enzymatic hydrolysis of various pretreated biomass. The applied technologies included disk-mill, ${ }^{12,21,22}$ PFI mill, ${ }^{22-24}$ food processor blender, ${ }^{22}$ extruder, ${ }^{22,25,26}$ Szego mill, $^{23}$ etc. It was reported that all of the refining technologies could improve the biomass digestibility by $10-20 \% .^{22}$ Among them, the PFI mill was a commonly used laboratory mechanical refiner, which could provide accurate control and induce homogeneous refining effects on the substrate. ${ }^{27}$ As a lab equipment, the PFI mill could refine a small quantity of biomass and be easily handled. Also, the PFI mill was usually used to simulate a disc refiner, which could be used at a large scale, although the refining of the PFI mill differed from disc and conical refiners (PFI mill imposed a greater proportion of compressive to shear forces). It has been know that the PFI mill is a high-energy and low-intensity refiner and normally uses 10 times the energy typically consumed in industrial refiners. ${ }^{27}$

Received: January 14, 2014

Revised: April 3, 2014

Accepted: May 1, 2014

Published: May 1, 2014 
Table 1. Component of Corn Cob before and after Deacetylation

\begin{tabular}{|c|c|c|c|c|c|c|c|}
\hline \multicolumn{2}{|c|}{ sample } & \multicolumn{5}{|c|}{ chemical composition (wt \%) } & \multirow[b]{2}{*}{$R_{\text {solid }}(\%)$} \\
\hline & alkali charge $(\mathrm{mmol} / \mathrm{g}$ of od substrate) & $C_{\text {glucan }}\left(R_{\text {glucan }}\right)$ & $C_{\text {xylan }}\left(R_{\text {xylan }}\right)$ & $C_{\text {arabin }}\left(R_{\text {arabin }}\right)$ & $C_{\text {acetyl }}\left(R_{\text {deacetylation }}\right)$ & $C_{\text {lignin }}\left(R_{\text {delignification }}\right)$ & \\
\hline \multirow[t]{4}{*}{$\mathrm{NaOH}^{a}$} & 0.8 & $44.72(92.9)$ & $40.98(84.50)$ & $3.62(90.81)$ & $0.08(97.89)$ & $5.06(63.68)$ & 72.50 \\
\hline & 0.6 & $42.02(99.44)$ & $39.95(93.84)$ & $3.15(90.02)$ & $0.30(90.99)$ & $8.36(31.64)$ & 82.59 \\
\hline & 0.4 & $40.06(100.43)$ & $38.45(95.68)$ & $3.29(99.60)$ & $0.62(80.27)$ & $8.29(28.19)$ & 87.49 \\
\hline & 0.2 & $39.23(101.72)$ & 37.49 (96.49) & $3.11(97.38)$ & $1.80(40.77)$ & $8.90(20.23)$ & 90.49 \\
\hline \multirow[t]{4}{*}{$\mathrm{Na}_{2} \mathrm{CO}_{3}{ }^{a}$} & 0.8 & $39.32(98.23)$ & $37.81(93.76)$ & $3.08(92.92)$ & $0.79(74.95)$ & $8.66(25.24)$ & 87.19 \\
\hline & 0.6 & $37.5(99.71)$ & $36.96(97.55)$ & $2.79(89.59)$ & $1.02(65.58)$ & $8.00(26.50)$ & 92.80 \\
\hline & 0.4 & $39.33(101.19)$ & $37.57(95.94)$ & $3.09(96.00)$ & $1.76(42.53)$ & $8.47(24.70)$ & 89.79 \\
\hline & 0.2 & $38.77(100.75)$ & $37.1(95.69)$ & $2.97(93.20)$ & $2.33(23.16)$ & $8.76(21.34)$ & 90.69 \\
\hline \multirow[t]{4}{*}{$\mathrm{Ca}(\mathrm{OH})_{2}$} & 0.8 & $39.6(96.76)$ & $37.06(89.89)$ & $3.36(99.15)$ & $0.13(95.97)$ & $7.97(32.70)$ & 85.28 \\
\hline & 0.6 & $39.44(97.91)$ & $37.05(91.30)$ & $2.75(82.44)$ & $0.57(82.04)$ & $8.62(26.02)$ & 86.64 \\
\hline & 0.4 & $39.27(98.25)$ & $37.26(92.54)$ & 3.17 (95.78) & $0.86(72.69)$ & $8.63(25.37)$ & 87.32 \\
\hline & 0.2 & $38.51(98.60)$ & $36.51(92.79)$ & $3.11(96.16)$ & $1.90(38.26)$ & $8.83(21.88)$ & 89.36 \\
\hline raw materia & & 34.90 & 35.16 & 2.89 & 2.75 & 10.10 & \\
\hline
\end{tabular}

${ }^{a}$ Measured as $\mathrm{Na}_{2} \mathrm{O}$.

Therefore, in this work, to improve the XOS yield and efficiently use cellulose from corn cob, a combined deacetylation and PFI refining pretreatment process was established and a two-stage enzymatic hydrolysis for the pretreated corn cob were carried out. The two-stage enzymatic hydrolysis was also used to evaluate the effectiveness of the combined pretreatment method. In the first stage of enzymatic hydrolysis (stage 1), just xylanase was added to release XOS, while in the second stage of hydrolysis (stage 2), both cellulase and $\beta$-glucosidase were used to digest the solid residue obtained from stage 1, aiming for the full utilization of the corn cob.

\section{MATERIALS AND METHODS}

Materials. The corn cob was harvested in 2012, in Shandong province (China), further milled by an agriculture use hammer mill, and screened to obtain the fraction with a particle size between the meshes of 20 and 80 (i.e., $0.18-0.85 \mathrm{~mm}$ ). The screened corn cob was stored in sealed plastic bags at room temperature to be ready for the component analysis and pretreatment. The solid content of the prepared corn cob was $93.9 \%$.

Xylanase was generously provided by Habio Enzyme (Mianyang, Sichuan province, China), and its activity was 38 international units $(\mathrm{IU}) / \mathrm{mL}$. Celluclast $1.5 \mathrm{~L}$ (cellulase) and Novozyme $188(\beta$ glucosidase) were bought from Sigma-Aldrich (St. Louis, MO). The activities of cellulase and $\beta$-glucosidase were 121 filter paper units $(\mathrm{FPU}) / \mathrm{mL}$ and $741 \mathrm{IU} / \mathrm{mL}$, respectively. All of the enzyme activities were measured using the methods reported by Ghose. ${ }^{28}$ Other chemicals were of analytical quality and were bought from Sinopharm Chemical Reagent Co., Ltd. All of the enzymes and chemicals were used as received.

Deacetylation Treatment. The deacetylation treatment of corn cob was carried out following the previous procedure, ${ }^{14}$ with slight modifications. Briefly, $10 \mathrm{~g}$ of screened dry corn cob was put into a 250 $\mathrm{mL}$ bottle with $120 \mathrm{~mL}$ of alkali solution of different alkali charge. The alkali charge ranged from 0.2 to $0.8 \mathrm{mmol} / \mathrm{g}$ of oven-dried (od) substrate. Then, the bottle was placed in an incubator shaker with 160 rpm at $70{ }^{\circ} \mathrm{C}$ for $3 \mathrm{~h}$. After deacetylation, the corn cob was filtered and washed with tap water 4 times through a 300-mesh nylon cloth until neutrality. For each time, the ratio of washing water/deacetylated corn cob was 3:1 (w/w). Finally, the solid samples were collected and weighed for further analysis and tests. As a control, the corn cob was treated in water at $70{ }^{\circ} \mathrm{C}$ for $3 \mathrm{~h}$. In deacetylation treatment, two weak bases $\mathrm{Na}_{2} \mathrm{CO}_{3}$ and $\mathrm{Ca}(\mathrm{OH})_{2}$ and one strong base $\mathrm{NaOH}$ were used. The alkali charges of $\mathrm{NaOH}$ and $\mathrm{Na}_{2} \mathrm{CO}_{3}$ were measured as $\mathrm{Na}_{2} \mathrm{O}$ (mmol/g of od substrate), and the alkali charges of $\mathrm{Ca}(\mathrm{OH})_{2}(\mathrm{mmol} /$ $\mathrm{g}$ of od substrate) were considered to be the same as that of $\mathrm{Na}_{2} \mathrm{O}$ in this work, because although the solubility of $\mathrm{Ca}(\mathrm{OH})_{2}$ is low (about
$1.4 \times 10^{-3} \mathrm{mmol} / \mathrm{L}$ in $\left.70^{\circ} \mathrm{C}\right)$, the ionization degree is high $\left(k_{1}=3.72\right.$ $\times 10^{-3}$, and $k_{2}=3.98 \times 10^{-2}$ ). For example, $0.6 \mathrm{mmol}$ of $\mathrm{NaOH}$ or $\mathrm{Na}_{2} \mathrm{CO}_{3}$ (as $\left.\mathrm{Na}_{2} \mathrm{O}\right) / \mathrm{g}$ of substrate and $0.6 \mathrm{mmol}$ of $\mathrm{Ca}(\mathrm{OH})_{2} / \mathrm{g}$ of substrate could be considered to have the same alkali charge.

Mechanical Refining. To further increase enzymatic digestibility, the deacetylated and washed corn cob was modified by a PFI beating machine (mode PL11-00, Xianyang TEST Equipment Co., Ltd., Xianyang, China). The beating conditions were as follows: beating revolution was 4000 according to the studies by Chen et al. ${ }^{14}$ and Jones et al. ${ }^{23}$; beating consistency was $10 \mathrm{wt} \%$; revolution speed was $1400 \mathrm{rpm}$; and beating gap was $0.24 \mathrm{~mm}$.

Enzymatic Hydrolysis. The corn cob was hydrolyzed in two stages. In stage 1 , the corn cob was first hydrolyzed by xylanase. A total of $20 \mathrm{~mL}$ of a mixture of substrate (with $2 \%$ solid loading), sodium citrate buffer $(0.1 \mathrm{M}, \mathrm{pH} 4.8)$, and xylanase was added in a $50 \mathrm{~mL}$ bottle for the National Renewable Energy Laboratory (NREL) procedure. $^{29}$ The xylanase dose was $66 \mathrm{IU} / \mathrm{g}$ of od biomass. The xylanase hydrolysis was carried out at $50{ }^{\circ} \mathrm{C}$ with the agitation at 120 $\mathrm{rpm}$ for $24 \mathrm{~h}$. Upon completion, the hydrolyzate was separated by filtration, and the solid residue was washed and further hydrolyzed by cellulase and $\beta$-glucosidase in stage 2 . All hydrolyzed residues were added together with sodium citrate buffer $(0.1 \mathrm{M}, \mathrm{pH} 4.8)$, cellulase, and $\beta$-glucosidase to a $50 \mathrm{~mL}$ bottle. Then, the slurry was diluted to 20 $\mathrm{mL}$. The cellulase and $\beta$-glucosidase doses were $18 \mathrm{FPU} / \mathrm{g}$ and $9 \mathrm{IU} / \mathrm{g}$ of od biomass, respectively, on the basis of the corn cob added in stage 1. The other conditions were the same as stage 1 . After $48 \mathrm{~h}$ of hydrolysis, the hydrolyzate was collected by filtration to be ready for sugar analysis.

Analytical Methods. Glucan, xylan, acetyl, and lignin contents of biomass were determined using the NREL procedure. ${ }^{30}$ The oligosaccharide and monosaccharide in the hydrolyzate were examined by high-performance liquid chromatography (HPLC, model 1200, Agilent, Santa Clara, CA) on a carbohydrate analysis column (Waters SunFire, $4.6 \times 250 \mathrm{~mm}, 5 \mu \mathrm{m}$ ) with $50 \mathrm{mg} / \mathrm{L}$ ethylenediaminetetraacetic acid (EDTA) calcium salts as the mobile phase. A $10 \mu \mathrm{L}$ sample of the hydrolyzate was injected into the column, and XOS were detected by a refractive index detector. Glucose, xylose, arabinose (Sigma, St. Louis, MO), xylobiose, xylotriose, and xylotetraose (Suntory Co., Ltd., Kyoto, Japan), with retention times of 9.7, 10.8, $12.2,8.9,7.7$, and $7.0 \mathrm{~min}$, respectively, were used as standards.

The crystallinities of corn cobs were measured using a Bruker D8 ADVANCE X-ray diffractometer (Bruker Co., Germany). The specimen was prepared by placing approximately $0.1 \mathrm{~g}$ of the freezedried and milled biomass sample on a glass sample holder and then placing a drop of acetone on the sample to fix it on the holder. The specimen was scanned at $2^{\circ} / \mathrm{min}$ from $2 \theta=10-26^{\circ}$ with a step size of $0.05^{\circ}$. 


\section{RESULTS AND DISCUSSION}

Effect of the Pretreatment on Structural Features of Corn Cob. Table 1 shows the compositions of native and deacetylated corn cobs, as well as the recovery or removal rate of the corresponding component. In most cases, the deacetylation process could not efficiently remove the lignin, which was a main barrier of enzymatic hydrolysis, except using $\mathrm{NaOH}$ at an alkali charge of $0.8 \mathrm{mmol} / \mathrm{g}$ of substrate. A total of $63 \%$ delignification was achieved when using $0.8 \mathrm{mmol}$ of $\mathrm{NaOH} / \mathrm{g}$ of substrate, while the lignin removal at other conditions was just $20-32 \%$. This was probably due to the fact that the acetyl groups were easier to remove compared to lignin. A lower dosage of $\mathrm{NaOH}$ (e.g., $0.6 \mathrm{mmol} / \mathrm{g}$ of substrate) could only sufficiently remove acetyl groups, while a higher dosage of $\mathrm{NaOH}$ (e.g., $0.8 \mathrm{mmol} / \mathrm{g}$ of substrate) could also provide enough alkali to remove much more lignin during deacetylation. Under these relatively mild alkaline conditions, the recovery rates of glucan and xylan after deacetylation were all higher than 92 and 84\%, respectively (Table 1), because there was only a small amount of carbohydrates degraded in deacetylation (particularly for glucan). The glucan and xylan compositions of the samples were all improved by the removal of ash, lignin, soluble sugars, and other water-soluble extractives. Also, as shown in Table 2, after deacetylation,

Table 2. Crystallinity Index of Corn Cob before and after Deacetylation and PFI Refining

\begin{tabular}{|c|c|c|c|}
\hline & $\begin{array}{c}\text { raw } \\
\text { corn } \\
\text { cob }\end{array}$ & $\begin{array}{l}\text { deacetylated } \\
\text { corn } \operatorname{cob}^{a}\end{array}$ & $\begin{array}{l}\text { deacetylated and PFI } \\
\text { refined corn } \operatorname{cob}^{a}\end{array}$ \\
\hline $\begin{array}{l}\text { crystallinity index } \\
\text { (CrI) (\%) }\end{array}$ & 35.7 & 37.1 & 34.3 \\
\hline $\begin{array}{l}\text { cellulose crystallinity } \\
\text { (CCr) (\%) }\end{array}$ & 102.3 & 94.5 & 87.3 \\
\hline
\end{tabular}

${ }^{a}$ Deacetylation condition: $\mathrm{Ca}(\mathrm{OH})_{2}$ of $0.4 \mathrm{mmol} / \mathrm{g}$ of substrate alkali charge.

there was a slight increase $(1-2 \%)$ of the crystallinity index of corn cob. This was because of the removal of amorphous components (i.e., acetyl groups and lignin) in deacetylated corn cob. ${ }^{24}$ However, the decrease of cellulose crystallinity after deacetylation was due to the increase of the cellulose content in the deacetylated corn cob (Table 1). After PFI refining, both the crystallinity index and cellulose crystallinity of deacetylated corn cob were decreased (Table 2). This was mainly due to the destruction of the crystalline region in cellulose caused by the compression and shear forces during PFI refining. ${ }^{18}$

Unlike the delignification and crystallinity, the deacetylation increased significantly with the increase of alkali charge. For example, when the alkali charge was increased from 0.2 to 0.8 $\mathrm{mmol} / \mathrm{g}$ of substrate using $\mathrm{Na}_{2} \mathrm{CO}_{3}$, the degree of deacetylation was increased from 23 to $74 \%$. For the two weak alkali $\left[\mathrm{Na}_{2} \mathrm{CO}_{3}\right.$ and $\left.\mathrm{Ca}(\mathrm{OH})_{2}\right]$, the effect of $\mathrm{Ca}(\mathrm{OH})_{2}$ on deacetylation was closer to that of $\mathrm{NaOH}$ compared to $\mathrm{Na}_{2} \mathrm{CO}_{3}$, because of the higher $\mathrm{pH}$ derived from $\mathrm{Ca}(\mathrm{OH})_{2}$ at the same alkali charge. For instance, $96 \%$ deacetylation could be achieved after $\mathrm{Ca}(\mathrm{OH})_{2}$ treatment with the alkali charge of 0.8 $\mathrm{mmol} / \mathrm{g}$ of substrate at $70{ }^{\circ} \mathrm{C}$ for $3 \mathrm{~h}$, suggesting that the mild process could efficiently remove the acetyl groups in corn cob.

Two-Stage Enzymatic Hydrolysis of Deacetylated Corn Cob. Low solids (2\%) enzymatic hydrolysis was performed to test the digestibility of deacetylated corn cob in the near-ideal conditions, in which the mass transfer limitations between enzymes and substrate as well as the inhibition from products could be negligible. Figures 1 and 2 show the effect of the alkali charge on the percentage of enzymatic hydrolysis and the sugar yields of the two-stage hydrolysis of corn cobs, which were deacetylated by $\mathrm{NaOH}, \mathrm{Na}_{2} \mathrm{CO}_{3}$, and $\mathrm{Ca}(\mathrm{OH})_{2}$, respectively. Both the percentage of enzymatic hydrolysis and the sugar yields were increased with the increase of the alkali charge. When the corn cobs were deacetylated by $\mathrm{NaOH}$, $\mathrm{Na}_{2} \mathrm{CO}_{3}$, and $\mathrm{Ca}(\mathrm{OH})_{2}$ at the alkali charge of $0.8 \mathrm{mmol} / \mathrm{g}$ of substrate, the hydrolysis percentages of xylan in stage 1 were 93, 71, and $85 \%$, respectively. The hydrolysis percentages of glucan in stage 2 were 86,58 , and $74 \%$, respectively. For the case of $\mathrm{Ca}(\mathrm{OH})_{2}$, although the enzymatic hydrolysis percentage of xylan was lower than that for $\mathrm{NaOH}$, the sugar yield $(0.293$ $\mathrm{g} / \mathrm{g}$ of corn cob at $0.8 \mathrm{mmol} / \mathrm{g}$ of substrate) was similar to the sugar yield using $\mathrm{NaOH}(0.300 \mathrm{~g} / \mathrm{g}$ of corn cob at $0.8 \mathrm{mmol} / \mathrm{g}$ of substrate) because of the high recovery of xylan after the
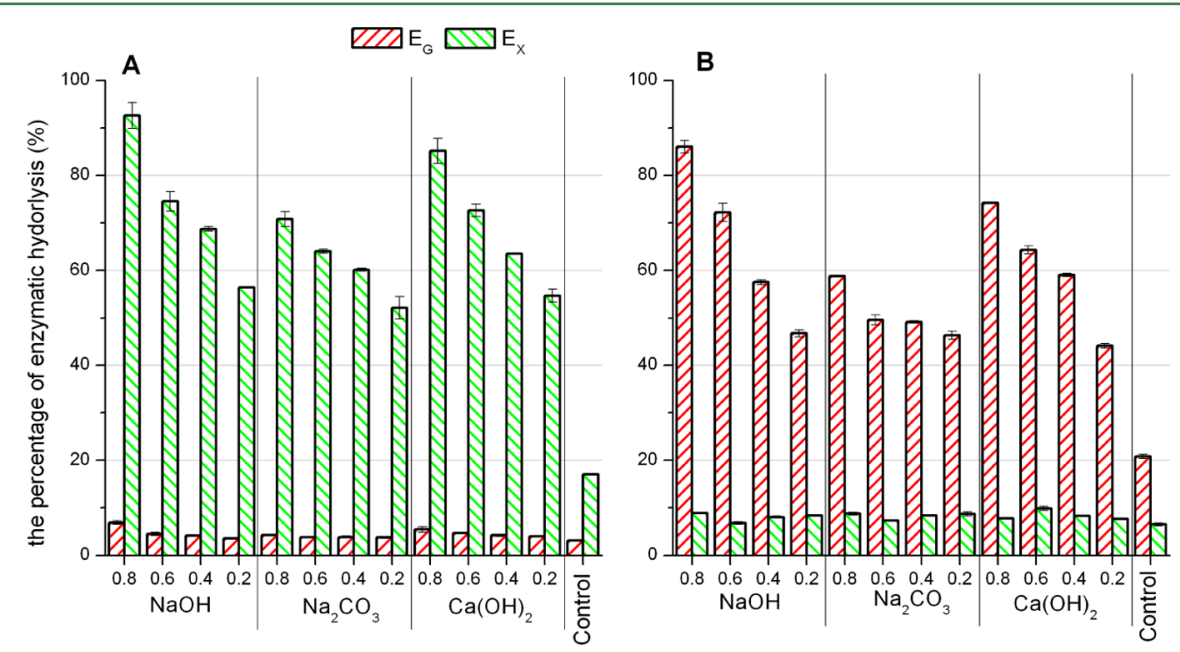

Figure 1. Percentages of enzymatic hydrolysis $\left(E_{\mathrm{G}}\right.$ and $\left.E_{\mathrm{X}}\right)$ of the two-stage hydrolysis of corn cob deacetylated by different bases and alkali charges. (A) Percentages of enzymatic hydrolysis of stage 1 (xylanase hydrolysis). (B) Percentages of enzymatic hydrolysis of stage 2 (cellulase and $\beta$ glucosidase hydrolysis). Values of $0.8-0.2$, samples deacetylated with the alkali charge of $0.8-0.2 \mathrm{mmol} / \mathrm{g}$ of substrate $\left(\mathrm{NaOH}\right.$ and $\mathrm{Na}_{2} \mathrm{CO}_{3}$ were calculated as $\mathrm{Na}_{2} \mathrm{O}$ ); control, water-treated sample. 


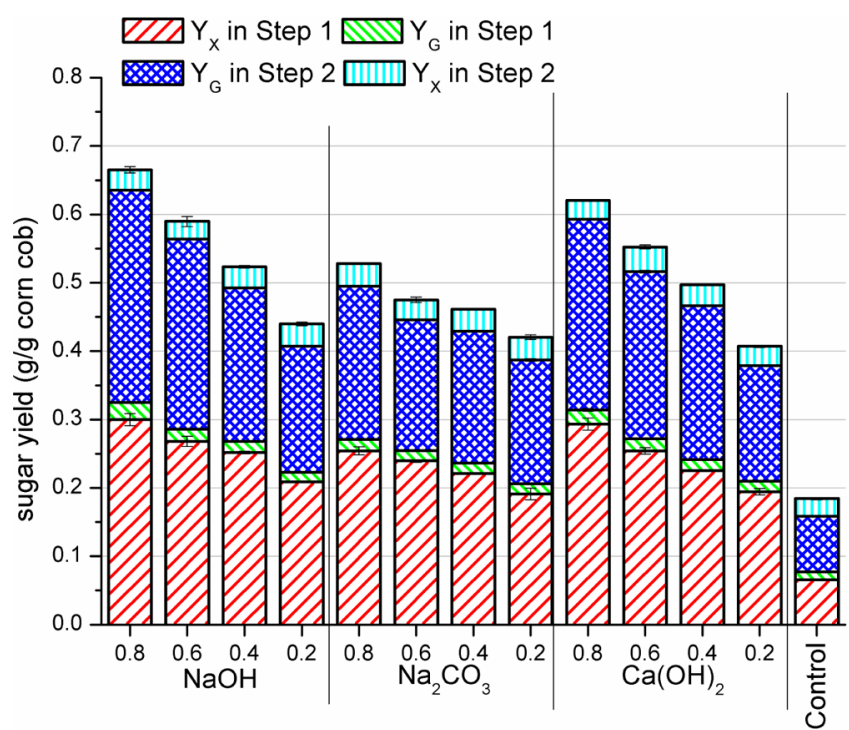

Figure 2. Sugar yields $\left(Y_{\mathrm{G}}\right.$ and $\left.Y_{\mathrm{X}}\right)$ of the two-stage hydrolysis of corn cob deacetylated by different bases and alkali charges. Values of $0.8-$ 0.2 , samples deacetylated with the alkali charge of $0.8-0.2 \mathrm{mmol} / \mathrm{g}$ of substrate $\left(\mathrm{NaOH}\right.$ and $\mathrm{Na}_{2} \mathrm{CO}_{3}$ were calculated as $\left.\mathrm{Na}_{2} \mathrm{O}\right)$; control, water-treated sample.

deacetylation process using $\mathrm{Ca}(\mathrm{OH})_{2}$. In comparison to other cellulosic material (such as corn stover ${ }^{14}$ and aspen wood ${ }^{31}$ ), the corn cob could be highly digested in enzymatic hydrolysis after mild deacetylation treatment without any severe pretreatment (such as acid-assisted steam explosion ${ }^{11}$ and acidified sodium chloride delignification ${ }^{12,21}$ ) because of the low lignin and high hemicellulose contents. In the two-stage hydrolysis, most xylan was separated in stage 1 by xylanase, leaving most of the glucan in the hydrolyzed solid residue because of the selectivity of xylanase. All of the proportions of sugars in the hydrolyzates after stage 1 were similar to the proportion deacetylated by $\mathrm{Ca}(\mathrm{OH})_{2}$ with the alkali charge of $0.8 \mathrm{mmol} / \mathrm{g}$ of substrate (Table 3 ). XOS accounted for about $50 \%$ soluble

Table 3. Sugar Content of the Hydrolyzate after Xylanase Hydrolysis $^{a}$

$\begin{array}{ccccccc}\text { saccharide } & \text { glucose } & \text { xylose } & \mathrm{X}^{b} & \mathrm{X}^{b} & \mathrm{X} 4-\mathrm{X} 7^{b} & \text { arabinose } \\ \begin{array}{c}\text { content } \\ (\text { wt \%) }\end{array} & 6.25 & 33.93 & 41.88 & 10.12 & 2.47 & 5.33 \\ \begin{array}{c}\text { conversion } \\ (\%)^{d}\end{array} & 5.3 & 27.7 & 36.5 & 9.0 & 2.2 & \\ & & & & & & \end{array}$

${ }^{a}$ From the PFI refined corn cob [deacetylated by $\mathrm{Ca}(\mathrm{OH})_{2}$ with the alkali charge of $0.8 \mathrm{mmol} / \mathrm{g}$ of substrate]. ${ }^{6} \mathrm{X} 2$, xylobiose; $\mathrm{X} 3$, xylotriose; and $\mathrm{X} 4-\mathrm{X} 7$, xylotetraose, xylopentaose, xylohexaose, and xyloheptaose. ${ }^{c}$ On the basis of the total sugar weight in the hydrolyzate. ${ }^{d}$ On the basis of xylan or glucan in the raw corn cob.

sugar in the hydrolyzate. The comparatively low percentage of XOS could be caused by the long hydrolysis time, which could obtain a higher xylan yield because XOS could be further hydrolyzed into xylose by $\beta$-xylosidase in crude xylanase. The enzymatic digestions of the solid residues (stage 2) obtained from xylanase hydrolysis had a trend similar to stage 1 . Because most of the digestible xylan was removed in stage 1 by xylanase, the percent of xylose in the hydrolyzate of stage 2 was much lower than the hydrolyzate directly obtained from the traditional one-stage enzymatic hydrolysis without the xylanremoving process. As presented in Table 4, the final sugar
Table 4. Comparison of the Sugar Yields Obtained from Different Enzymatic Hydrolysis Processes ${ }^{a}$

\begin{tabular}{|c|c|c|c|c|c|c|c|}
\hline \multicolumn{6}{|c|}{ two-stage hydrolysis } & \multirow{2}{*}{\multicolumn{2}{|c|}{$\begin{array}{c}\text { one-stage } \\
\text { hydrolysis } \\
(48 \mathrm{~h})^{c}\end{array}$}} \\
\hline \multicolumn{2}{|c|}{ stage $1(24 \mathrm{~h})$} & \multicolumn{2}{|c|}{ stage $2(48 \mathrm{~h})$} & \multicolumn{2}{|c|}{ total yield ${ }^{b}$} & & \\
\hline$Y_{\mathrm{G} 1}$ & $Y_{\mathrm{X} 1}$ & $Y_{\mathrm{G} 2}$ & $Y_{\mathrm{X} 2}$ & $Y_{\mathrm{G}}$ & $Y_{\mathrm{X}}$ & $Y_{\mathrm{G}}$ & $Y_{\mathrm{X}}$ \\
\hline 0.021 & 0.293 & 0.278 & 0.028 & 0.299 & 0.321 & 0.336 & 0.340 \\
\hline
\end{tabular}

${ }^{a}$ Hydrolysis substrate: PFI refined corn cob [deacetylated by $\mathrm{Ca}(\mathrm{OH})_{2}$ at the alkali charge of $0.8 \mathrm{mmol} / \mathrm{g}$ of substrate]. ${ }^{b}$ The total yield of two-stage hydrolysis $\left(Y_{\mathrm{G}}\right.$ or $\left.Y_{\mathrm{X}}\right)$ was calculated as follows: $Y_{\mathrm{G}}=Y_{\mathrm{G} 1}+$ $Y_{\mathrm{G} 2} ; Y_{\mathrm{X}}=Y_{\mathrm{X} 1}+Y_{\mathrm{X} 2} \cdot{ }^{c}$ Enzyme doses: cellulase, $18 \mathrm{FPU} / \mathrm{g}$ of od biomass; $\beta$-glucosidase, $9 \mathrm{IU} / \mathrm{g}$ of od biomass; and xylanase, $66 \mathrm{IU} / \mathrm{g}$ of od biomass.

yields obtained from the two-stage enzymatic hydrolysis were somewhat lower compared to the traditional one-stage hydrolysis. This was likely because used cellulase and $\beta$ glucosidase contained some xylanases, which had the ability to hydrolyze xyloligomers into xylose, thus removing the inhibition from xyloligomers during hydrolysis. This was in agreement with the fact that there were no xyloligomers detected in the hydrolyzate after one-stage hydrolysis. On the other hand, in the one-stage hydrolysis, three enzymes (cellulase, $\beta$-glucosidase, and xylanase) were added together, and the addition of xylanase may reduce the ineffective adsorption of cellulase to xylan and lignin, thus leading to the relative increase of cellulase activity. ${ }^{18,32-34}$ Therefore, a higher final sugar yield could be achieved by the one-stage enzymatic hydrolysis. However, in stage 1 of the two-stage enzymatic hydrolysis, used xylanase had a lower ability to hydrolyze xyloligomers to xylose. Thus, many xyloligomers could be obtained after the hydrolysis of stage 1. Furthermore, in stage 2, the glucan yield was lower compared to the one-stage hydrolysis. This was possibly due to the relatively increased proportion of lignin in the xylan-deprived corn cob residue. The increased proportion of lignin might increase the ineffective adsorption of cellulase to lignin, thus lowering the glucan yield. However, although the sugar yields from the twostage hydrolysis were lower than the one-stage hydrolysis, using xylanase and cellulase to "tailor" the deacetylated corn cob in two separated processes could make the component of the product more simplified, which is good for the further microbial or chemical utilizations. In addition, the optimization of enzymatic hydrolysis and the study of the inhibition of the XOS product in high solid loading $(\geq 15 \%)$ hydrolysis will be conducted in the future.

Impact of Refining on the Enzymatic Hydrolysis. As shown in Figures 3 and 4, the enzymatic hydrolysis percentages of xylan $\left(E_{\mathrm{X}}\right)$ in stage 1 , the enzymatic hydrolysis percentages of glucan $\left(E_{\mathrm{G}}\right)$ in stage 2 , and the total sugar yields $\left(Y_{\mathrm{S}}\right)$ were all increased after PFI refining. The increased extents of sugar yields ranged from 0.023 to $0.212 \mathrm{~g} / \mathrm{g}$ of corn cob (Figure 4), which were comparable to the previous reports. ${ }^{18}$ However, the increased extents of hydrolysis percentages and sugar yields for the samples treated at hash conditions were lower than that for the samples treated with mild conditions. For example, as shown in Figure 4A, 9.7\% improvement of the enzymatic hydrolysis percentage of xylan could be obtained for the samples treated with $0.2 \mathrm{~g}$ of $\mathrm{Ca}(\mathrm{OH})_{2} / \mathrm{g}$ of substrate, while only $3.6 \%$ improvement could be achieved for the samples treated with $0.8 \mathrm{~g}$ of $\mathrm{Ca}(\mathrm{OH})_{2} / \mathrm{g}$ of substrate. Also, for the 

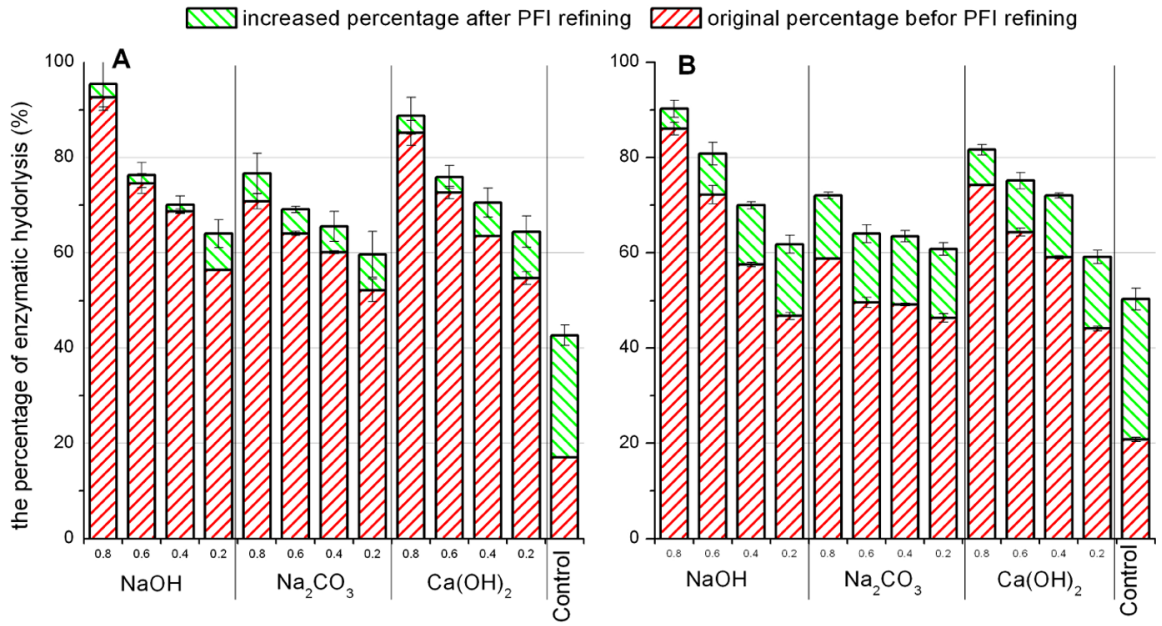

Figure 3. Effect of PFI refining on the rates of enzymatic hydrolysis $\left(E_{\mathrm{G}}\right.$ and $\left.E_{\mathrm{X}}\right)$ of the two-stage hydrolysis of deacetylated corn cob. (A) $E_{\mathrm{X}}$ of stage 1 (xylanase hydrolysis). (B) $E_{\mathrm{G}}$ of stage 2 (cellulase and $\beta$-glucosidase hydrolysis) Values of $0.8-0.2$, samples deacetylated with the alkali charge of $0.8-0.2 \mathrm{mmol} / \mathrm{g}$ of substrate $\left(\mathrm{NaOH}\right.$ and $\mathrm{Na}_{2} \mathrm{CO}_{3}$ were calculated as $\left.\mathrm{Na}_{2} \mathrm{O}\right)$; control, water-treated sample.

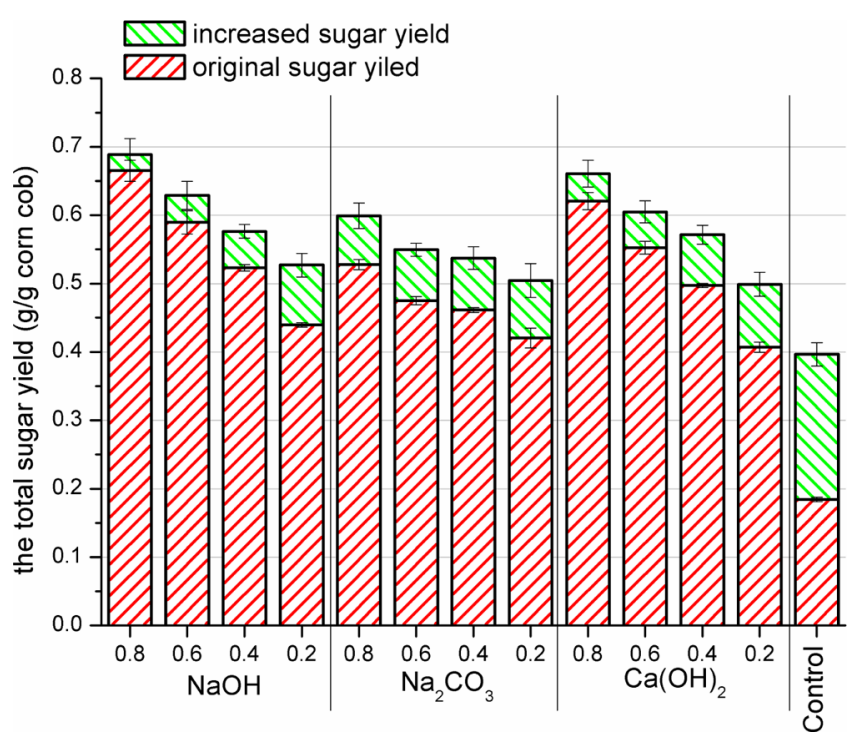

Figure 4. Effect of PFI refining on the total sugar yields (all of the sugars in hydrolyzate) obtained from the two-stage hydrolysis of deacetylated corn cob. Values of $0.8-0.2$, samples deacetylated with the alkali charge of $0.8-0.2 \mathrm{mmol} / \mathrm{g}$ of substrate $\left(\mathrm{NaOH}\right.$ and $\mathrm{Na}_{2} \mathrm{CO}_{3}$ were calculated as $\mathrm{Na}_{2} \mathrm{O}$ ); control, water-treated sample.

control sample, the total sugar yield was $0.212 \mathrm{~g} / \mathrm{g}$ of corn cob, while after PFI refining, the total sugar yield could be 2.7 times higher than that of the unrefined sample (Figure 4). This was because the size reduction that resulted from the PFI refining increased the reactive surface area for enzymes, thus leading to an increase of xylan and glucan yields. ${ }^{18}$ On the other hand, the decrease of crystallinity of cellulose (Table 2) caused by the compression and shear force of the PFI mill could also make cellulose more digestible. ${ }^{13}$ In addition, as presented in Figure 4 , a total sugar yield of $0.661 \mathrm{~g} / \mathrm{g}$ of corn cob could be obtained from the samples treated by $0.8 \mathrm{mmol}$ of $\mathrm{Ca}(\mathrm{OH})_{2} / \mathrm{g}$ of substrate, which was comparable to the yield $(0.688 \mathrm{~g} / \mathrm{g}$ of corn cob) obtained from the sample treated by $\mathrm{NaOH}$ with the same alkali charge. This was due to the fact that higher sugar recovery could be achieved in the deacetylation process by the use of $\mathrm{Ca}(\mathrm{OH})_{2}$. Therefore, it can be concluded that $\mathrm{Ca}(\mathrm{OH})_{2}$ is the more appropriate alkali for deacetylation and the suitable alkali charge is $0.8 \mathrm{mmol} / \mathrm{g}$ of substrate based on the results obtained in this study. Other benefits using $\mathrm{Ca}(\mathrm{OH})_{2}$ are that (1) $\mathrm{Ca}(\mathrm{OH})_{2}$ is an inexpensive and milder base compared to $\mathrm{NaOH}$ and (2) $\mathrm{Ca}(\mathrm{OH})_{2}$ can be easily recovered. Although some calcium ions may precipitate as calcium salts, precipitated calcium could be removed by sufficient washing (e.g., using vacuum washing equipment at large-scale production) after deacetylation. Another possible solution to avoid the precipitation of calcium is to add a small amount of chelating agent (e.g., EDTA) before deacetylation, so that the released calcium ions could be chelated and then removed during washing.

Mass Balance Analysis. The overall process and mass balance for the combined deacetylation [on the basis of $\left.\mathrm{Ca}(\mathrm{OH})_{2}\right]$ and PFI refining pretreatment of corn cob plus the two-stage enzymatic hydrolysis are presented in Figure 5. For theoretical calculation, the sugar loss in PFI refining was neglected. As demonstrated in Figure 5, after $\mathrm{Ca}(\mathrm{OH})_{2}$ deacetylation (with the alkali charge of $0.8 \mathrm{mmol} / \mathrm{g}$ of substrate) and PFI refining, $79.8 \%$ xylan was hydrolyzed in

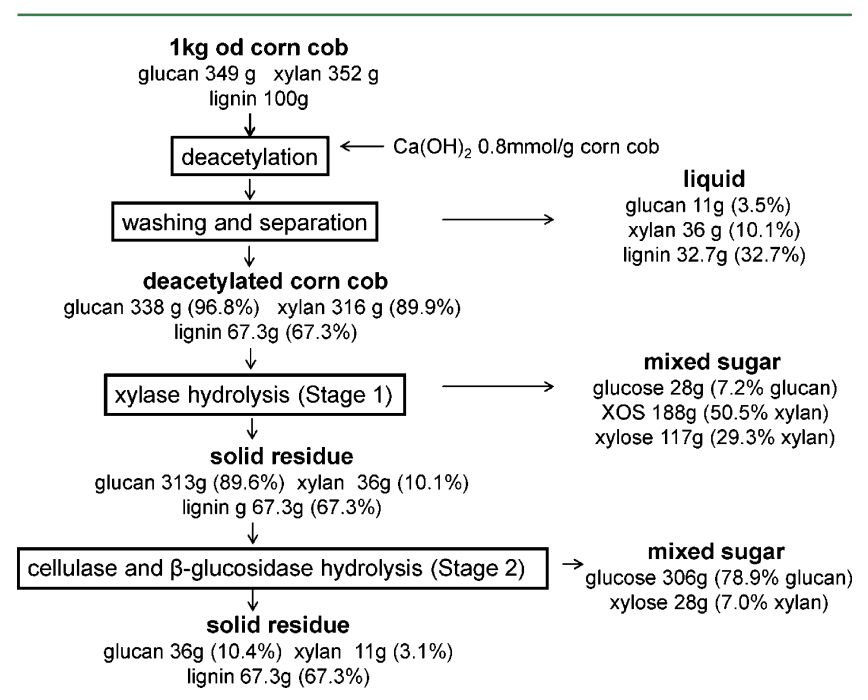

Figure 5. Mass balance of the overall process (deacetylation + PFI refining + two-stage hydrolysis). 
stage 1 of enzymatic hydrolysis and 50.5\% hemicellulose was converted to XOS. The cellulose in the solid residue separated from stage 1 could be highly digested by cellulase and $\beta$ glucosidase in stage 2 . In total, $86.8 \%$ xylan and $86.1 \%$ glucan in the raw corn cob were hydrolyzed in the two-stage enzymatic hydrolysis, indicating that the combined $\mathrm{Ca}(\mathrm{OH})_{2}$ deacetylation and PFI refining pretreatment process was a relatively effective method to improve the enzymatic digestion of corn cob. In addition, in comparison to the traditional one-stage enzymatic hydrolysis, the two-stage hydrolysis can make the resulting sugar products simpler and easier to be used in the downstream processes.

\section{ASSOCIATED CONTENT}

\section{S Supporting Information}

X-ray diffraction (XRD) pattern of raw corn cob (Figure S1) and detailed calculations. This material is available free of charge via the Internet at http://pubs.acs.org.

\section{AUTHOR INFORMATION}

\section{Corresponding Authors}

*Telephone/Fax: +86-532-80662725. E-mail: libin@qibebt.ac. cn.

*E-mail: penghui@qibebt.ac.cn.

\section{Funding}

This research was funded by the Natural Science Foundation of China (21206184, 31370582, and 21306216), the Shandong Provincial Natural Science Foundation for Distinguished Young Scholar (China) (JQ201305), and the National High Technology Research and Development Program ("863" Program) of China (2012AA022301).

\section{Notes}

The authors declare no competing financial interest.

\section{ABBREVIATIONS USED}

XOS, xylo-oligosaccharides; SPORL, sulfite pretreatment to overcome recalcitrance of lignocellulose; NREL, National Renewable Energy Laboratory; HPLC, high-performance liquid chromatography; $R_{\text {solid }}$ recovery rate of solid after deacetylation; $R_{\text {glucan }}$ recovery rate of glucan; $R_{\text {xylan }}$, recovery rate of xylan; $R_{\text {arabin }}$ recovery rate of arabinan; $D_{\text {delignification }}$ delignification percentage after deacetylation; $D_{\text {deacetylation }}$ deacetylation percentage after deacetylation; $E_{\mathrm{X}}$, enzymatic hydrolysis percentage of xylan; $E_{\mathrm{G}}$, enzymatic hydrolysis percentage of glucan; $Y_{\mathrm{X}}$, xylan yield; $Y_{\mathrm{G}}$, glucan yield; $Y_{\mathrm{S}}$, total sugar yield

\section{REFERENCES}

(1) Carvalho, A. F. A.; de Oliva Neto, P.; da Silva, D. F.; Pastore, G. M. Xylo-oligosaccharides from lignocellulosic materials: Chemical structure, health benefits and production by chemical and enzymatic hydrolysis. Food Res. Int. 2013, 51, 75-85.

(2) Chapla, D.; Pandit, P.; Shah, A. Production of xylooligosaccharides from corncob xylan by fungal xylanase and their utilization by probiotics. Bioresour. Technol. 2012, 115, 215-221.

(3) Aachary, A. A.; Prapulla, S. G. Value addition to corncob: Production and characterization of xylooligosaccharides from alkali pretreated lignin-saccharide complex using Aspergillus oryzae MTCC 5154. Bioresour. Technol. 2009, 100, 991-995.

(4) Yang, R.; Xu, S.; Wang, Z.; Yang, W. Aqueous extraction of corncob xylan and production of xylooligosaccharides. LWT-Food Sci. Technol. 2005, 38, 677-682.

(5) Akpinar, O.; Erdogan, K.; Bostanci, S. Enzymatic production of xylooligosaccharide from selected agricultural wastes. Food Bioprod. Process. 2009, 87, 145-151.
(6) Samanta, A. K.; Senani, S.; Kolte, A. P.; Sridhar, M.; Sampath, K. T.; Jayapal, N.; Devi, A. Production and in vitro evaluation of xylooligosaccharides generated from corn cobs. Food Bioprod. Process. 2012, 90, 466-474.

(7) Brienzo, M.; Carvalho, W.; Milagres, A. M. F. Xylooligosaccharides production from alkali-pretreated sugarcane bagasse using xylanases from Thermoascus aurantiacus. Appl. Biochem. Biotechnol. 2010, 162, 1195-1205.

(8) Mou, H. Y.; Orblin, E.; Kruus, K.; Fardim, P. Topochemical pretreatment of wood biomass to enhance enzymatic hydrolysis of polysaccharides to sugars. Bioresour. Technol. 2013, 142, 540-545.

(9) Li, B.; Liu, H.; Xu, H.; Pang, B.; Mou, H. Y.; Wang, H.; Mu, X. Characterization of the detailed relationships of the key variables in the process of the alkaline sulfite pretreatment of corn stover by multivariate analysis. BioResources 2014, 9, 2757-2771.

(10) Mou, H. Y.; Heikkilä, E.; Fardim, P. Topochemistry of alkaline, alkaline-peroxide and hydrotropic pretreatments of common reed to enhance enzymatic hydrolysis efficiency. Bioresour. Technol. 2013, 150, 36-41.

(11) Alvira, P.; Tomas-Pejo, E.; Ballesteros, M.; Negro, M. J. Pretreatment technologies for an efficient bioethanol production process based on enzymatic hydrolysis: A review. Bioresour. Technol. 2010, 101, 4851-4861.

(12) Zhu, J. Y.; Pan, X. J.; Wang, G. S.; Gleisner, R. Sulfite pretreatment (SPORL) for robust enzymatic saccharification of spruce and red pine. Bioresour. Technol. 2009, 100, 2411-2418.

(13) Chang, V. S.; Holtzapple, M. T. Fundamental factors affecting biomass enzymatic reactivity. Appl. Biochem. Biotechnol. 2000, 84-6, 5-37.

(14) Chen, X. W.; Tao, L.; Shekiro, J.; Mohaghaghi, A.; Decker, S.; Wang, W.; Smith, H.; Park, S.; Himmel, M. E.; Tucker, M. Improved ethanol yield and reduced minimum ethanol selling price (MESP) by modifying low severity dilute acid pretreatment with deacetylation and mechanical refining: 1) Experimental. Biotechnol. Biofuels 2012, 5, 60.

(15) Agger, J.; Vikso-Nielsen, A.; Meyer, A. S. Enzymatic xylose release from pretreated corn bran arabinoxylan: Differential effects of deacetylation and deferuloylation on insoluble and soluble substrate fractions. J. Agric. Food Chem. 2010, 58, 6141-6148.

(16) Selig, M. J.; Adney, W. S.; Himmel, M. E.; Decker, S. R. The impact of cell wall acetylation on corn stover hydrolysis by cellulolytic and xylanolytic enzymes. Cellulose 2009, 16, 711-722.

(17) Grohmann, K.; Mitchell, D. J.; Himmel, M. E.; Dale, B. E.; Schroeder, H. A. The role of ester groups in resistance of plant cell wall polysaccharides to enzymatic hydrolysis. Appl. Biochem. Biotechnol. 1989, 20-21, 45-61.

(18) Leu, S. Y.; Zhu, J. Y. Substrate-related factors affecting enzymatic saccharification of lignocelluloses: Our recent understanding. BioEnergy Res. 2013, 6, 405-415.

(19) Larsson, S.; Palmqvist, E.; Hahn-Hägerdal, B.; Tengborg, C.; Stenberg, K.; Zacchi, G.; Nilvebrant, N.-O. The generation of fermentation inhibitors during dilute acid hydrolysis of softwood. Enzyme Microb. Technol. 1999, 24, 151-159.

(20) Nigam, J. N. Development of xylose-fermenting yeast Pichia stipitis for ethanol production through adaptation on hardwood hemicellulose acid prehydrolysate. J. Appl. Microbiol. 2001, 90, 208215 .

(21) Zhu, W.; Zhu, J. Y.; Gleisner, R.; Pan, X. J. On energy consumption for size-reduction and yields from subsequent enzymatic saccharification of pretreated lodgepole pine. Bioresour. Technol. 2010, 101, 2782-2792.

(22) Chen, X.; Kuhn, E.; Wang, W.; Park, S.; Flanegan, K.; Trass, O.; Tenlep, L.; Tao, L.; Tucker, M. Comparison of different mechanical refining technologies on the enzymatic digestibility of low severity acid pretreated corn stover. Bioresour. Technol. 2013, 147, 401-408.

(23) Jones, B. W.; Venditti, R.; Park, S.; Jameel, H.; Koo, B. Enhancement in enzymatic hydrolysis by mechanical refining for pretreated hardwood lignocellulosics. Bioresour. Technol. 2013, 147, $353-60$. 
(24) Mou, H. Y.; Li, B.; Fardim, P. Pretreatment of corn stover with modified hydrotropic method to enhance enzymatic hydrolysis. Energy Fuels 2014, DOI: 10.1021/ef5001634.

(25) Liu, C.; van der Heide, E.; Wang, H.; Li, B.; Yu, G.; Mu, X. Alkaline twin-screw extrusion pretreatment for fermentable sugar production. Biotechnol. Biofuels 2013, 6, 97.

(26) Zhang, Y.; Hou, T.; Li, B.; Liu, C.; Mu, X.; Wang, H. Acetonebutanol-ethanol production from corn stover pretreated by alkaline twin-screw extrusion pretreatment. Bioprocess Biosyst. Eng. 2013, 1-9.

(27) Kerekes, R. J. Characterizing refining action in PFI mills. Tappi J. 2005, 4 (3), 9-14.

(28) Ghose, T. K. Measurement of cellulase activities. Pure Appl. Chem. 1987, 59, 257-268.

(29) Selig, M.; Weiss, N.; Ji, Y. Enzymatic Saccharification of Lignocellulosic Biomass; National Renewable Energy Laboratory (NREL): Golden, CO, 2008; NREL/TP-510-42629.

(30) Sluiter, A.; Hames, B.; Ruiz, R.; Scarlata, C.; Sluiter, J.; Templeton, D.; Crocker, D. Determination of Structure Carbohydrates and Lignin in Biomass; National Renewable Energy Laboratory (NREL): Golden, CO, 2008; NREL/TP-510-42618.

(31) Kong, F. R.; Engler, C. R.; Soltes, E. J. Effects of cell-wall acetate, xylan backbone, and lignin on enzymatic-hydrolysis of aspen wood. Appl. Biochem. Biotechnol. 1992, 34-5, 23-35.

(32) Qing, Q.; Wyman, C. E. Supplementation with xylanase and $\beta$ xylosidase to reduce xylo-oligomer and xylan inhibition of enzymatic hydrolysis of cellulose and pretreated corn stover. Biotechnol. Biofuels 2011, 4, 18.

(33) Segal, L.; C. J; Martin, A. E.; Conrad, C. M. An empirical method for estimating the degree of crystallinity of native cellulose using the X-ray diffractometer. Text. Res. J. 1959, 29, 786-794.

(34) Xu, F.; Shi, Y. C.; Wang, D. X-ray scattering studies of lignocellulosic biomass: A review. Carbohydr. Polym. 2013, 94, 904917. 